\title{
Intrarectally administered polaprezinc attenuates the development of dextran sodium sulfate-induced ulcerative colitis in mice
}

\author{
ZHAOYANG LIU ${ }^{1 *}$, WENBO XIE ${ }^{2 *}$, MINGRU LI ${ }^{2}$, JING LIU $^{1}$, XIAO LIANG ${ }^{1}$ and TAO LI $^{3}$ \\ ${ }^{1}$ National Cancer Center/National Clinical Research Center for Cancer/Cancer Hospital, \\ Chinese Academy of Medical Sciences and Peking Union Medical College, Beijing 100021; \\ ${ }^{2}$ Jilin Province Broadwell Pharmaceutical Co., Ltd., Liaoyuan, Jilin 130000; ${ }^{3}$ Institute of Basic Medical Sciences of \\ Chinese Academy of Medical Sciences and Peking Union Medical College, Beijing 100005, P.R. China
}

Received January 10, 2019; Accepted September 24, 2019

DOI: $10.3892 / \mathrm{etm} .2019 .8155$

\begin{abstract}
Polaprezinc (PZ), a chelate of zinc and L-carnosine, has been widely used in the treatment of gastric ulcers since 1994. In recent years, researchers have found PZ to have a beneficial effect on various experimentally induced models of colitis in mice. In the present study, $6 \%$ dextran sodium sulfate (DSS) was used to induce a model of ulcerative colitis (UC) in Institute of Cancer Research mice. The therapeutic effect and mechanism of PZ action in a model of UC was studied in order to provide an experimental basis for the clinical application of PZ in UC treatment. The effect of PZ on UC was evaluated in five groups of mice: A vehicle control only group, a DSS model control group (DSS, 6\%), a validated treatment control group (DSS 6\% + Mesalamine), a low-dose PZ treatment group (DSS 6\% + PZ $60 \mathrm{mg} / \mathrm{kg}$ ) and a high-dose PZ group (DSS 6\% + PZ $120 \mathrm{mg} / \mathrm{kg}$ ). After the animals were sacrificed, blood was collected and the serum levels of NF- $\kappa B$ and tumor necrosis factor- $\alpha$ (TNF- $\alpha$ ) were measured. Changes in histology were observed by light microscopy. The protein levels of AKT, phosphorylated AKT and heat shock protein 70 (HSP70) were determined by western blot analysis. The results suggested that PZ reduced the DSS-induced increase in the inflammatory proteins TNF- $\alpha$ and NF- $\mathrm{KB}$ in the UC model. The high-dose of PZ also increased the HSP70 protein level, inhibited AKT phosphorylation in a DSS-induced UC animal model, and decreased white blood cell and neutrophil \%
\end{abstract}

Correspondence to: Dr Zhaoyang Liu, National Cancer Center/National Clinical Research Center for Cancer/Cancer Hospital, Chinese Academy of Medical Sciences and Peking Union Medical College, 17 Panjiayuan Nanli, Chaoyang, Beijing 100021, P.R. China

E-mail: liuzhaoy@cicams.ac.cn

\section{${ }^{*}$ Contributed equally}

Key words: polaprezinc, ulcerative colitis, dextran sodium sulfate, mesalamine, NF- $\mathrm{B}$, tumor necrosis factor- $\alpha$, serine/threonine-specific protein kinase AKT phosphorylation, heat shock protein 70 counts compared to levels in an untreated DSS control group. Histopathology indicated that the mice of the DSS model group had irregular colonic villi, a large number of inflammatory cells and mucosal damage, whereas mice of the group treated with PZ had small intestinal villus morphology and their villi showed signs of recovery from the damage of UC. The results of the present study indicated that PZ significantly alleviates DSS-induced UC in mice, relieves diarrhea, and inhibits the phosphorylation of inflammatory factors and the inflammatory AKT signaling pathway.

\section{Introduction}

Ulcerative colitis (UC) is a refractory, relapsing and potentially malignant inflammatory disease, and is one of the main types of inflammatory bowel disease (IBD) (1). In recent years, the incidence of UC in China has risen, mostly in young adults, exhibiting regional differences and genetic tendencies, and has become subject to an increasing amount of research in the field of gastroenterology $(2,3)$. Dextran sodium sulfate (DSS) is widely used to induce UC in model mice for study (4). The symptoms in mice with DSS-induced UC are very similar to those of human UC, suggesting that it is an ideal model for study. These symptoms include disruption to the epithelial cell barrier, colitis induced by altered DNA replication, inhibition of the growth of epithelial cells, induction of macrophage activation, increased release of cytokines and disruption to the balance of gut microflora (5). The disease has become a target of research into new therapies, due to the fact it causes recurrent attacks, has a poor therapeutic response, leads to prolonged illness and has the possibility of developing into cancer $(6,7)$. The main goals in the clinical treatment of UC are to improve interactions between the symbiotic mucosal flora and the intestinal mucosa, to prevent the activation of lymphocytes, to induce the production of regulatory $\mathrm{T}$ cells, to inhibit the inflammatory response and concomitant production of inflammatory cytokines, and to repair damaged mucosa. Mesalamine (MES) is currently the first-choice drug for UC, as it can be used to both cause and maintain the remission of UC (8-10). Meta-analyses indicated that the effective rate and remission rate of UC patients treated with MES was better than that in a placebo group $(11,12)$. However, although only a small amount of MES reaches the 
colon, it often produces adverse reactions, such as abdominal pain, diarrhea and nephrotoxicity (13-15). Research is therefore focused on developing a high-efficiency and low-toxicity treatment. In treatment of UC, the new application of old drugs may play a role in future clinical practice $(5,16)$.

PZ is a chelate compound of zinc and L-carnosine, and has been used in the treatment of gastric ulcers in Japan since 1994 (17). Researchers have found that it has a beneficial effect in various experimentally induced models of colitis in mice (18). The mechanism of action of PZ in the treatment of UC may involve induction of heat shock protein (HSP) production, inhibition of the inflammatory response, anti-oxidation and cell membrane stabilization $(19,20)$. In the present study DSS was used to induce a UC model in mice. These mice were then used to explore the mechanisms of the therapeutic effect of PZ on UC induced by DSS, and its influence on inflammatory AKT signaling.

\section{Materials and methods}

Experimental drugs. PZ was obtained from the Jilin Broadwell Pharmaceutical Co. Ltd. in $5 \mathrm{~g}$ bags, batch number 25-160512 (Fig. 1). A pH 6.8 PZ balanced salt solution was prepared, and mice received $\mathrm{PZ}$ via enema, at a dose of $120 \mathrm{mg} / \mathrm{kg}$ body weight or $60 \mathrm{mg} / \mathrm{kg}$ body weight. As a positive control drug, MES was obtained (Sunflower Pharmaceutical Group of Jiamusi Luling Pharmaceutical Co., Ltd.) as enteric-coated tablets, containing $0.25 \mathrm{~g}$ raw material/tablet (batch no. 170306). The mice were given $300 \mathrm{mg} / \mathrm{kg}$ MES by enema. MES was ground into a powder using a pestle and mortar and dissolved in $0.9 \%$ aseptic sodium chloride solution.

DSS was obtained from the Shanghai Yisheng Biotechnology Co., Ltd. (lot no. D97990), as a white or grayish white powder, mice received DSS dissolved in $\mathrm{H}_{2} \mathrm{O}$ via intragastric administration of $0.2 \mathrm{ml} / 10 \mathrm{~g}$ body weight. three times per day (Table I).

Experimental animals. Male inbred Institute of Cancer Research (ICR) mice of specific pathogen free grade (age 6-8 weeks; weight, 17-19 g; 8 mice per group leading to a total of 40 mice) were obtained from the National Institute for Food and Drug Control in China [experimental animal quality certificate no. SCXK (Beijing, China) 2014-0013]. Food and water was available ad libitum throughout the experiment. The mice were kept at $20-25 \pm 3^{\circ} \mathrm{C}$ at a relative humidity of $40-60 \%$ and on a $12 \mathrm{~h}$ light/dark cycle.

UC model induction and sample collection. ICR mice were randomly divided into five groups of 8 mice per group (Table I). The groups were vehicle control (intragastric $\mathrm{H}_{2} \mathrm{O}$ ), UC model control, UC + MES, UC + low-dose (L) PZ and UC + high-dose $(\mathrm{H}) \mathrm{PZ}$. The UC model mice were intragastrically administered DSS at $3.6 \mathrm{~g} / \mathrm{kg} /$ day, three times per day for 7 consecutive days, while the vehicle control mice received the equivalent dose of $\mathrm{H}_{2} \mathrm{O}$. In the UC + MES group, $300 \mathrm{mg} / \mathrm{kg}$ MES was intrarectally administered once per day for 10 days. PZ was intrarectally administered once per day for 10 days, at $120 \mathrm{mg} / \mathrm{kg}$ in PZ H group, and at $60 \mathrm{mg} / \mathrm{kg}$ in the PZ L group. The vehicle group received the equivalent dose of vehicle by the same method and at the same time intervals. The experimental animals were observed daily for 10 days (Fig. 1B).
Approximately $24 \mathrm{~h}$ after the last treatment administration, and following $\mathrm{CO}_{2}$ anesthesia, the animals were killed by cervical dislocation. After the blood $(\sim 0.5 \mathrm{ml})$ was taken from the fundus vein cluster of each mouse, the serum was collected by centrifugation for $5 \mathrm{~min}$, at $1,788.8 \mathrm{xg}$ and $4^{\circ} \mathrm{C}$. The serum was then stored at $-80^{\circ} \mathrm{C}$. Serum levels of NF- $\kappa \mathrm{B}$ and TNF- $\alpha$ were determined within 3 days of collection.

Animal hemogram analysis. At the end of the experiment, blood ( 0.1 ml) was taken from the fundus vein cluster of each mouse put into 20 units of heparin (Shanghai Biochemical Co., Ltd.) and the hemogram was measured using an automatic blood analyzer (Sysmex Hematology Analyzer KX-21; Hitachi, Ltd.) within $2 \mathrm{~h}$.

Diarrhea scoring. The diarrhea of mice was observed during the experimental period and the scores were recorded and confirmed as follows: 0 , no diarrhea; 1 , mild diarrhea (perianal staining); 2, moderate diarrhea (hind legs, upper and lower abdomen staining) and 3, severe diarrhea (hind legs and whole abdomen stained, or the mouse had persistent defecation). Observers were not blinded, but maintained objectivity.

Colon tissue fixation and hematoxylin and eosin $(H \& E)$ staining. The colonic tissue of each mouse was fixed with neutral $10 \%$ formalin at room temperature for $48 \mathrm{~h}$, embedded in paraffin and then sectioned with a microtome to obtain 4-5 $\mu$ m-thick paraffin sections. Dewaxed sections were then stained with H\&E, as previously described (21), and the tissue morphological changes were visualized by light microscopy using an Olympus PM-6 microscope (Olympus Corporation).

Mouse ELISA. NF- $\kappa \mathrm{B}$ (cat. no. DG30647M) and TNF- $\alpha$ (cat. no. DG30048M) ELISA kits were supplied by Beijing Dongge Biotech Co., Ltd. and ELISAs were performed following the manufacturer's instructions. The kits were single-step sandwich ELISAs. Serum samples, standard samples and horseradish peroxidase (HRP)-labeled antibodies were successively added into the wells of a 96-well plate. After incubation and thorough washing, TMB chromogenic substrate was added into each well, which was converted into a blue compound by reduction with the HRP attached to the antibody. This color change allowed for quantitative deduction of the protein concentration in the samples. Optical density was determined using a Tecan Infinite F50 microplate reader (Tecan Group Ltd.) to measure the absorbance at a wavelength of $450 \mathrm{~nm}$, and was used to calculate the concentration of each group of samples.

Western blot analysis of the expression of $A K T, p-A K T$ and HSP70 in mouse colonic tissue. A segment of the colon of each mouse (from the ileocecal valve to a fixed site before the beginning of the rectum) was added to cell lysis solution [prepared using $50 \mathrm{mM}$ Tris base, $150 \mathrm{mM} \mathrm{NaCl}$ and $0.1 \%$ SDS $(0.303 \mathrm{~g}$ Tris base, $0.4383 \mathrm{~g} \mathrm{NaCl}, 0.05 \mathrm{~g} \mathrm{SDS}$ and $40 \mathrm{ml} \mathrm{H}_{2} \mathrm{O}$, using $\mathrm{HCl}$ to adjust $\mathrm{pH}$ to $8.0 \mathrm{in}$ a $50 \mathrm{ml}$ volume)] and the supernatant was collected after centrifugation at $16,770 \mathrm{x}$ g for $10 \mathrm{~min}$, at $4^{\circ} \mathrm{C}$. The total protein concentration in each sample was determined using a Bradford protein assay. A total of $10 \mu \mathrm{g}$ of protein was loaded into each lane of a 10\% SDS-PAGE gel. After SDS-PAGE the proteins were transferred onto a PVDF membrane. The 


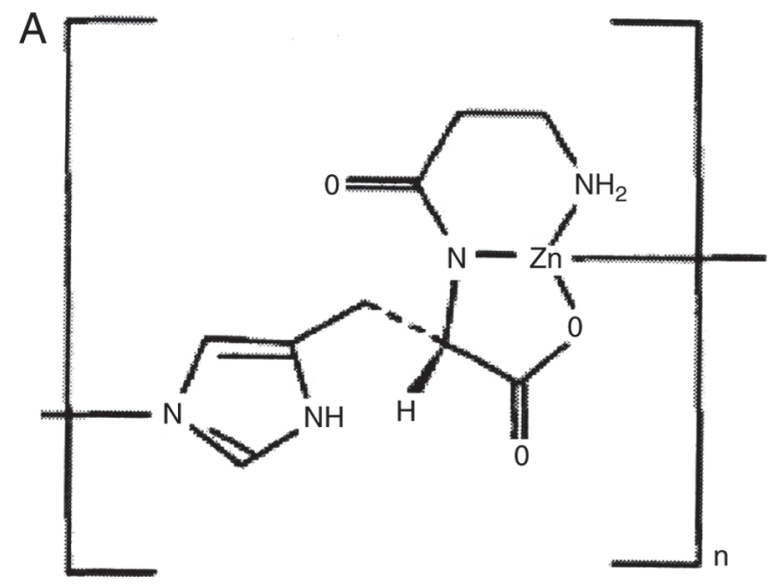

B

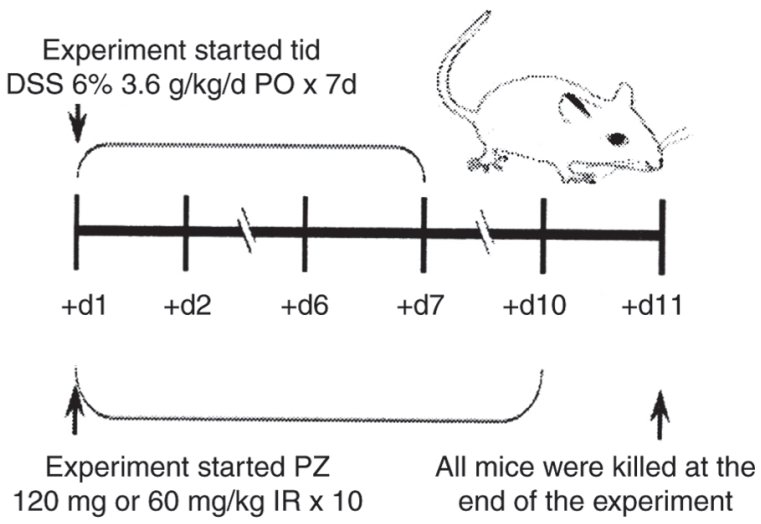

Figure 1. Chemical structure of polaprezinc and experimental scheme. (A) Chemical structure of polaprezinc. (B) Mode and time of administration of DSS during the experimental period. DSS, dextran sodium sulfate; PZ, polaprezinc; IR, intrarectal administration; d, day.

membrane was blocked with $5 \%$ skim milk powder in TBST $\left(0.1 \%\right.$ Tween) for $1 \mathrm{~h}$ at $25^{\circ} \mathrm{C}$. Cells were then incubated with a 1:300 dilution of primary antibody (cat. no. AB26297; Abbkine Scientific Co., Ltd.) or a 1:1,000 dilution of loading control antibody (cat. no. AC21215; Abbkine Scientific Co., Ltd.) overnight at $4^{\circ} \mathrm{C}$. The membranes were washed before they were incubated with a 1:3,000 dilution of HRP-conjugated secondary antibody (cat. no. ZB-2305; Beijing Zhongshan Jinqiao Biotechnology Co., Ltd.) for $1 \mathrm{~h}$ at room temperature. Blots were then visualized using an ECL kit (Beijing Roby Biotechnology Co., Ltd.; RBU 117-100). The densitometry was calculated using ImageJ (version no. 20150116; National Institutes of Health).

Statistical analysis. Data (from 8 samples per group) are expressed as the mean \pm SD. Statistical significance was evaluated using comparisons between groups analyzed by one-way ANOVA followed by the least significant difference post hoc test. All statistical analyses were performed with SPSS 17.0 (SPSS, Inc.). $\mathrm{P}<0.05$ was considered to indicate a statistically significant difference.

\section{Results}

After 3 days of administration of DSS, the body weight of the mice increased and there was a significant weight difference between the DSS-treated mice and the normal control group mice $(\mathrm{P}<0.01$; Table II). After administration of DSS, diarrhea occurred and weight gain slowed down. DSS was found to induce diarrhea in mice after intragastric administration, and PZ inhibited this DSS-induced diarrhea. Compared with the DSS model group, there was significant reduction in diarrhea in the PZ L group $(\mathrm{P}<0.05)$ and diarrhea was mild in the $\mathrm{PZ} \mathrm{H}$ group $(\mathrm{P}<0.01$; Table III).

PZ reduced the release of the inflammatory factors TNF- $\alpha$ and NF- $\kappa$ B in mice from the DSS-induced UC model, compared with that in mice from the DSS control group $(\mathrm{P}<0.05)$. High dose PZ increased HSP70 protein expression and inhibited the phosphorylation of AKT, an important mediator of inflammatory signaling, compared with UC model controls, though these changes were not statistically significant (Table IV and Fig. 2).
A hemogram of mice with DSS-induced UC showed that the symptoms and pathology were similar to those in humans with UC (19), and the inflammation was accompanied by an increase in the count of leukocytes and neutrophils in peripheral blood, which was similar to that observed in humans with UC. The results also showed that the white blood cell and neutrophil \% counts were increased in mice from the DSS-induced UC model group compared with the vehicle control group, and decreased after treatment with PZ (Table V).

Histopathological observations in mice from the DSS-induced UC model revealed that their colonic villi were irregular and that they had an increased number of inflammatory cells and mucosal damage in comparison with the vehicle control group. The continuity of their intestinal mucosa was disrupted and a large number of inflammatory cells were found to have infiltrated, as the arrow shows. By contrast, observations of the mice from the PZ-treated group revealed that their villi were intact and that they only showed mild colonic mucosal inflammation (Fig. 3).

\section{Discussion}

UC is a chronic recurrent form of IBD, characterized by diffuse inflammation and ulceration. The main goals of the clinical treatment of UC are to improve the interaction between the mucosal symbiotic bacteria and intestinal mucosa, prevent the activation of lymphocytes, induce production of regulatory $\mathrm{T}$ cells, inhibit inflammatory reactions and concomitant production of inflammatory cytokines and repair the damaged mucosa. The cascade of mucosal inflammation in UC, and the imbalance between proinflammatory cytokines, including interleukin (IL)-1, IL-6, IL-8 and tumor necrosis factor- $\alpha$, and anti-inflammatory cytokines are important linked events in the pathogenesis of UC.

PZ is a chelate compound composed of L-carnosine and zinc, which has been widely used in Japan since 1994 for the treatment of gastric ulcers. PZ stimulates mucus secretion and antioxidant production, stabilizes cell membranes, induces the production of HSPs and heme oxygenases, and can protect against gastric mucosal ulcers induced by various agents, as well as promoting healing. In recent 
Table I. Mouse experimental grouping and means of drug administration.

\begin{tabular}{|c|c|c|c|}
\hline Group & Drug doses administered & Drug administration modes & Duration of drug administration \\
\hline \multirow[t]{2}{*}{ Vehicle control } & $0 \mathrm{MES} / \mathrm{PZ}$ & N/A & N/A \\
\hline & 0 DES & N/A & N/A \\
\hline \multirow[t]{2}{*}{ UC only } & $0 \mathrm{MES} / \mathrm{PZ}$ & N/A & N/A \\
\hline & $3.6 \mathrm{~g} / \mathrm{kg} /$ day DSS & $\mathrm{PO}$ & Three times/day for 7 days \\
\hline \multirow[t]{2}{*}{$\mathrm{UC}+\mathrm{MES}$} & $300 \mathrm{mg} / \mathrm{kg} \mathrm{MES}$ & IR & Once a day for 10 days \\
\hline & $3.6 \mathrm{~g} / \mathrm{kg} /$ day DSS & $\mathrm{PO}$ & Three times/day for 7 days \\
\hline \multirow[t]{2}{*}{$\mathrm{UC}+\mathrm{PZ} \mathrm{L}$} & $60 \mathrm{mg} / \mathrm{kg} \mathrm{PZ}$ & IR & Once a day for 10 days \\
\hline & $3.6 \mathrm{~g} / \mathrm{kg} /$ day DSS & $\mathrm{PO}$ & Three times/day for 7 days \\
\hline \multirow[t]{2}{*}{$\mathrm{UC}+\mathrm{PZ} \mathrm{H}$} & $120 \mathrm{mg} / \mathrm{kg} \mathrm{PZ}$ & IR & Once a day for 10 days \\
\hline & $3.6 \mathrm{~g} / \mathrm{kg} /$ day DSS & $\mathrm{PO}$ & Three times/day for 7 days \\
\hline
\end{tabular}

$\mathrm{N}=8$ mice/experimental group. DSS, dextran sodium sulfate; H, high-dose; IR, intrarectal; L, low-dose; MES, mesalamine; PZ, polaprezinc; UC, ulcerative colitis. PO, per os, intragastric administration.

Table II. Effect of PZ on mouse body weight in DSS-induced UC.

\begin{tabular}{lcccc}
\hline Group & Pre-experiment weight $(\mathrm{g})$ & DSS day 3 weight $(\mathrm{g})$ & DSS day 6 weight $(\mathrm{g})$ & DSS day 9 weight $(\mathrm{g})$ \\
\hline Vehicle control & $23.8 \pm 1.0$ & $29.4 \pm 1.8$ & $32.5 \pm 1.8$ & $34.1 \pm 1.8$ \\
UC only & $23.1 \pm 0.9$ & $25.1 \pm 1.1^{\mathrm{a}}$ & $26.6 \pm 1.4^{\mathrm{a}}$ & $27.1 \pm 1.8^{\mathrm{a}}$ \\
UC + MES & $23.0 \pm 1.2$ & $25.6 \pm 3.0^{\mathrm{a}}$ & $26.4 \pm 1.7^{\mathrm{a}}$ & $26.5 \pm 1.9^{\mathrm{a}}$ \\
UC + PZ L & $23.0 \pm 1.0$ & $25.3 \pm 2.6^{\mathrm{a}}$ & $26.0 \pm 1.8^{\mathrm{a}}$ & $27.2 \pm 1.3^{\mathrm{a}}$ \\
UC + PZ H & $23.2 \pm 1.0$ & $24.2 \pm 2.5^{\mathrm{a}}$ & $26.0 \pm 1.5^{\mathrm{a}}$ & $27.0 \pm 1.9^{\mathrm{a}}$ \\
\hline
\end{tabular}

$\mathrm{N}=8$ mice/experimental group. ${ }^{\mathrm{a}} \mathrm{P}<0.01$ vs. respective vehicle control. $\mathrm{DSS}$, dextran sodium sulfate; $\mathrm{H}$, high dose; L, low dose; MES, mesalamine; PZ, polaprezinc; UC, ulcerative colitis.

Table III. Effect of PZ diarrhea recovery in dextran sodium sulfate-induced UC mice.

\begin{tabular}{lcc}
\hline Group & $\begin{array}{c}\text { Individual mouse } \\
\text { diarrhea scores }\end{array}$ & $\begin{array}{c}\text { Mean diarrhea } \\
\text { score }\end{array}$ \\
\hline Vehicle control & $0,0,0,0,0,0,0,0$ & 0 \\
UC only & $1,1,1,1,1,1,1,2$ & $1.125 \pm 0.353$ \\
$\mathrm{UC}+$ MES & $1,1,1,0,0,0,0,0$ & $0.375 \pm 0.517^{\mathrm{a}}$ \\
$\mathrm{UC}+$ PZ L & $1,1,1,1,1,0,0,0$ & $0.625 \pm 0.517^{\mathrm{b}}$ \\
$\mathrm{UC}+\mathrm{PZ} \mathrm{H}$ & $1,1,1,0,0,0,0,0$ & $0.375 \pm 0.517^{\mathrm{a}}$ \\
\hline
\end{tabular}

$\mathrm{n}=8$ mice/experimental group. ${ }^{\mathrm{a}} \mathrm{P}<0.01$ vs. $\mathrm{UC}$ only; ${ }^{\mathrm{b}} \mathrm{P}<0.05$ vs. UC only. H, high-dose; L, low-dose; MES, mesalamine; PZ, polaprezinc; UC, ulcerative colitis.

years, researchers have found that $\mathrm{PZ}$ has a therapeutic effect on various experimentally-induced colitis models in mice $(18,19)$. The mechanism of action of PZ may involve the induction of HSPs, inhibition of the inflammatory process, antioxidant functions and cell membrane stabilization $(18,22-26)$. It has been reported that intrarectal administration of PZ can effectively protect against subserous injection-induced colitis in rats, and has a beneficial effect on ulcers during the healing stage $(27,28)$

DSS-induced acute colitis is a chemically-induced model of UC. The model is simple and practical, and has many similarities with human UC, thus it is widely used in UC research (29).

$\mathrm{NF}-\kappa \mathrm{B}$ is a universal transcription factor, which is involved in the regulation of many pro-inflammatory factors and plays an important role in the pathogenesis of IBD. The classic $\mathrm{NF}-\kappa \mathrm{B}$ activation pathway is related to the rapid production of a large number of pro-inflammatory mediators, such as cyclo-oxygenase 2 , IL-1 $\beta$ and IL-6, in acute inflammation in patients with IBD (30). Among the many inflammatory cytokines, TNF- $\alpha$, IL-1 $\beta$, IL- 6 and IL- 8 play a major role in inflammation (31). TNF- $\alpha$ is one of the most abundant early inflammatory mediators and can activate neutrophils and lymphocytes, promote neutrophil migration to the inflammatory region of the colon mucosa, increase the permeability of vascular endothelial cells, regulate tissue metabolic activity, promote the synthesis and release of other pro-inflammatory cytokines and immunomodulators and lead to enterocyte apoptosis. TNF- $\alpha$ also promotes platelet activating factor release, which accelerates thrombosis, leading to mucosal microcirculation disturbance and extensive damage to the colonic mucosa $(8,32)$. It has been reported that an increase in 
Table IV. Effect of PZ on levels of TNF- $\alpha, N F-\kappa B, H S P 70$ and AKT phosphorylation in dextran sodium sulfate-induced UC mice.

\begin{tabular}{llccc}
\hline Group & TNF- $\alpha(\mathrm{pg} / \mathrm{ml})$ & NF- $\kappa B(\mathrm{pg} / \mathrm{ml})$ & p-AKT/AKT ratio & HSP70 (grey value) \\
\hline Vehicle control & $60.28 \pm 8.27$ & $900.33 \pm 133.54$ & Not tested & Not tested \\
UC only & $84.82 \pm 7.40^{\mathrm{a}}$ & $1262.88 \pm 169.01^{\mathrm{a}}$ & $1.941 \pm 0.016$ & $0.484 \pm 0.013$ \\
$\mathrm{UC}+$ MES & $64.81 \pm 10.22^{\mathrm{b}}$ & $974.12 \pm 123.35^{\mathrm{b}}$ & $0.948 \pm 0.151$ & $1.335 \pm 0.020$ \\
$\mathrm{UC}+$ PZ L & $74.81 \pm 10.31^{\mathrm{a}, \mathrm{c}}$ & $1070.38 \pm 168.44^{\mathrm{d}}$ & $1.560 \pm 0.002$ & $1.219 \pm 0.003$ \\
$\mathrm{UC}+$ PZ H & $62.38 \pm 8.70^{\mathrm{b}}$ & $826.80 \pm 116.88^{\mathrm{b}}$ & $1.427 \pm 0.019$ & $1.577 \pm 0.015$ \\
\hline
\end{tabular}

$\mathrm{n}=8$ mice/experimental group. ${ }^{\mathrm{a}} \mathrm{P}<0.01$ vs. vehicle control; ${ }^{\mathrm{b}} \mathrm{P}<0.01 \mathrm{vs}$. $\mathrm{UC}$ only; ${ }^{\mathrm{c}} \mathrm{P}<0.05$ vs. UC only; ${ }^{\mathrm{d}} \mathrm{P}<0.05$ vs. vehicle control. $\mathrm{H}$, high-dose; HSP70, heat shock protein 70; L, low-dose; MES, mesalamine; p, phosphorylated; PZ, polaprezinc; TNF- $\alpha$, tumor necrosis factor- $\alpha$; UC, ulcerative colitis.

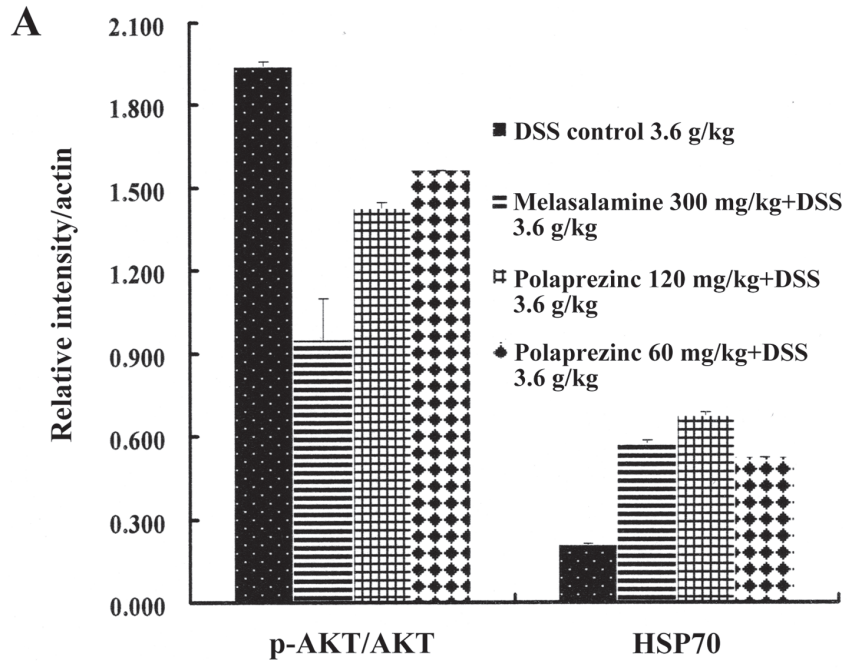

B

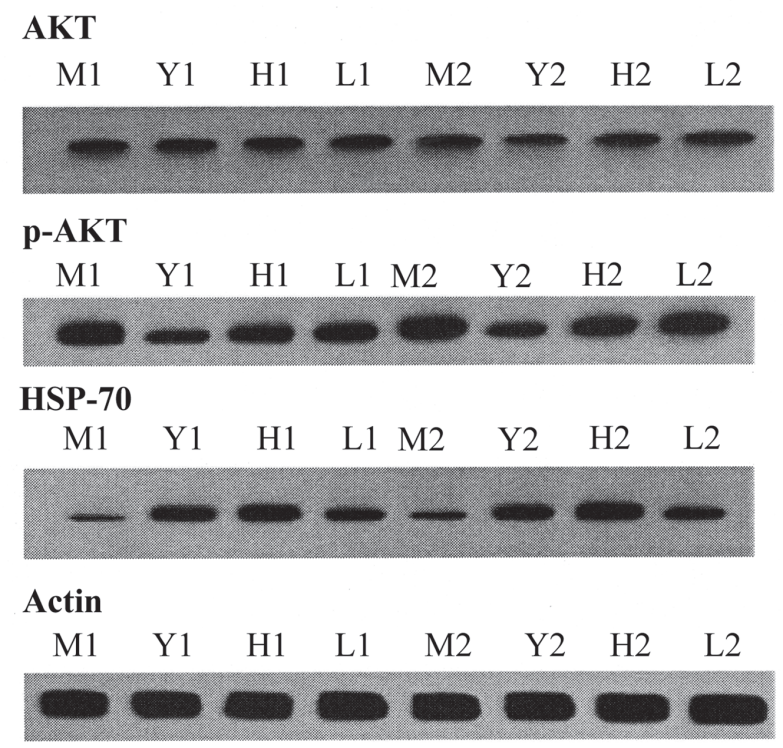

Figure 2. Relative levels of AKT/p-AKT and HSP70 in mouse colonic UC induced by DSS. (A) Relative levels of AKT/p-AKT and HSP70 normalized to $\beta$-actin determined from (B) western blot analysis. DSS, dextran sodium sulfate; M, UC model only; Y, UC model + mesalamine; $\mathrm{H}$, UC model + high-dose polaprezinc; L, UC model + low-dose polaprezinc; UC, ulcerative colitis; p, phosphorylated.

TNF- $\alpha$ levels in UC patient serum is related to exacerbation of the condition (33).
Table V. Effect of polaprezinc on the recovery of the blood hemogram in mice with UC induced by dextran sodium sulfate.

\begin{tabular}{lcc}
\hline Group & $\begin{array}{c}\text { Total WBC } \\
\left(\mathrm{x} 10^{9} / 1\right)\end{array}$ & $\begin{array}{c}\text { Neutrophil } \\
\text { granulocyte }(\%)\end{array}$ \\
\hline Vehicle control & $5.70 \pm 0.53$ & $23.33 \pm 1.94$ \\
UC only & $8.32 \pm 2.42^{\mathrm{a}}$ & $34.96 \pm 9.90^{\mathrm{a}}$ \\
$\mathrm{UC}+$ MES & $7.86 \pm 1.05$ & $31.36 \pm 11.08$ \\
$\mathrm{UC}+$ PZ L & $7.20 \pm 1.50$ & $27.54 \pm 10.86$ \\
$\mathrm{UC}+$ PZ H & $6.73 \pm 1.14$ & $19.4 \pm 6.50^{\mathrm{b}}$ \\
\hline
\end{tabular}

$\mathrm{n}=8$ mice/experimental group. ${ }^{\mathrm{a}} \mathrm{P}<0.05$ vs. vehicle control; ${ }^{\mathrm{b}} \mathrm{P}<0.05$ vs. UC only. H, high-dose; L, low-dose; MES, mesalamine; $\mathrm{PZ}$, polaprezinc; UC, ulcerative colitis.

HSPs are a family of highly conserved and ubiquitously expressed proteins. During infection, ischemia and other physiological stress conditions, HSP expression has a protective role. HSPs are key anti-inflammatory molecules, which play a role in preventing a physiological reaction (34). It has been reported that the expression of HSP in a colitis model was significantly increased after treatment with drugs $(35,36)$.

MES is a compound used in the treatment of UC, which has a beneficial effect, MES inhibits the function of various inflammatory mediators, such as leukotriene and prostaglandin, to suppresses intestinal inflammatory reactions, but widespread use in clinical practice is limited due to the potential for the development of drug dependence, long-term drug resistance and economic pressure on patients due to its high cost (37).

The results of the present study suggested that PZ may significantly improve the symptoms of DSS-induced UC in mice. PZ treatment appeared to reduce colon tissue hyperemia, edema and inflammatory responses. As these effects are related to the anti-inflammatory activity of PZ, it can be hypothesized that the mechanism mediating these effects involves the inhibition of inflammatory signaling via phosphorylated AKT and an increased HSP level. The present study was limited by the small sample size and the fact that only animal experiments could be carried out. Further research into the effect of PZ on UC should be carried out in the clinic.

The incidence of UC in China has been increasing year on year $(38,39)$. However, the emergence of new drugs, 

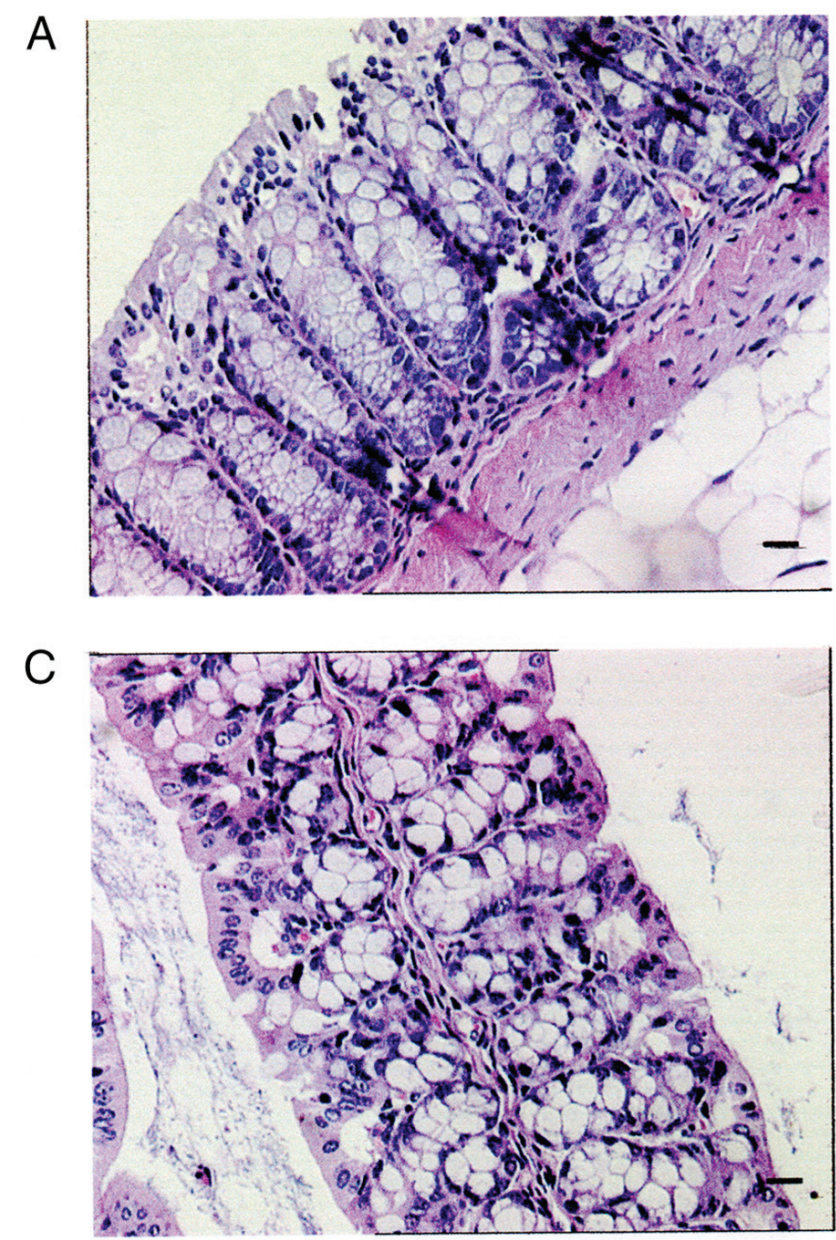
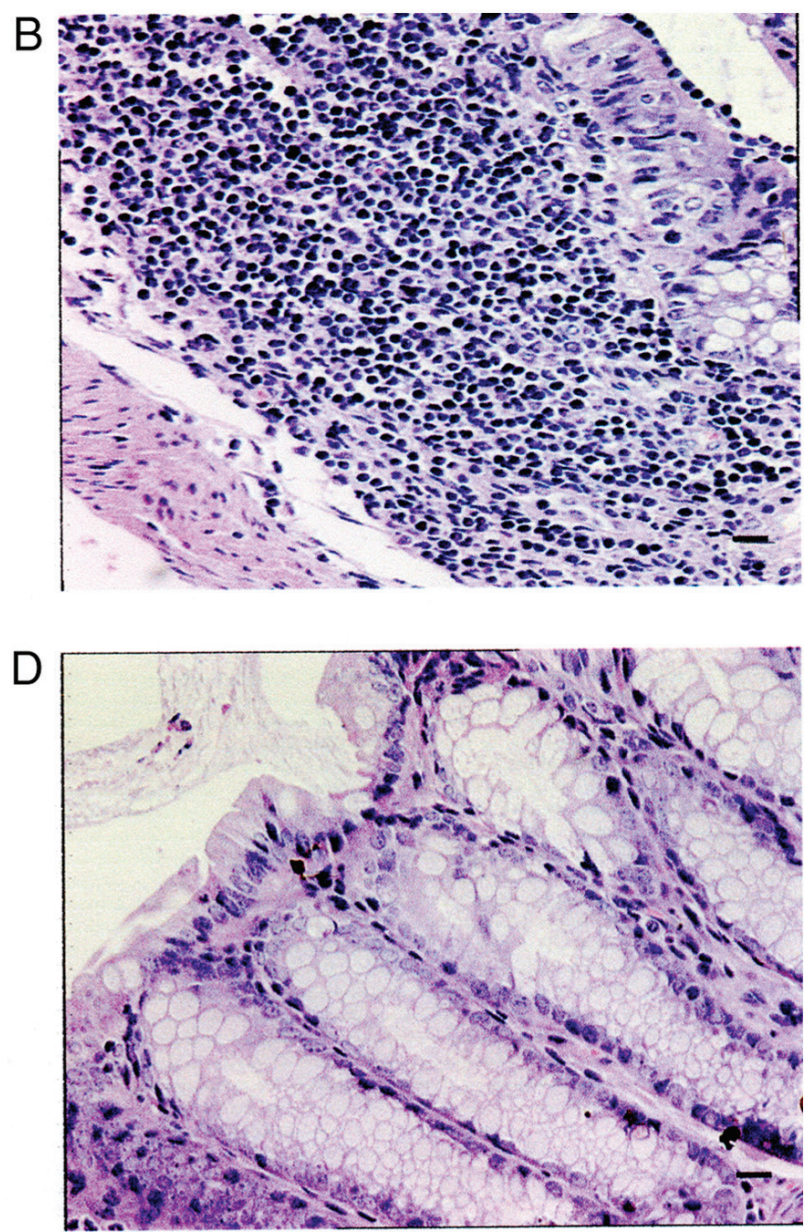

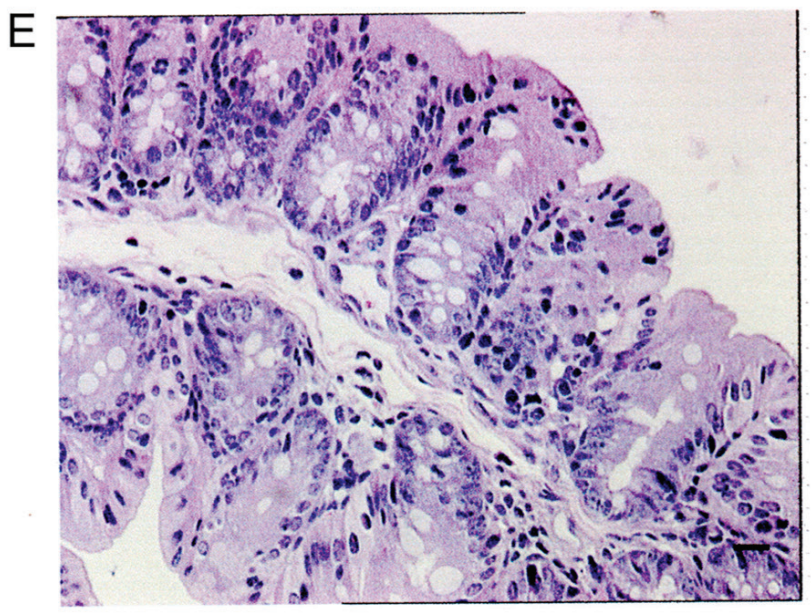

Figure 3. Representative images of colonic tissue in a mouse model of DSS-induced UC. The colon was taken from the same part of the colon in each experimental group, then cut open and fixed with $10 \%$ formalin, cut longitudinally into slices and stained with hematoxylin and eosin; the tissue structure of each layer was observed under light microscope (three fields of vision were examined per tissue slice). (A) Vehicle control group (untreated with DSS). Mucosa of the colonic tissue was intact and cells were arranged neatly. (B) UC model only group. Mucosal cell structure was destroyed and inflammatory cells had infiltrated. (C) UC model + mesalamine group. Cell structure appeared relatively stable. (D) UC model + H. Glandular cells were arranged neatly and had a clear structure. (E) UC model + L. Cells were ordered, though there were some signs of cell death. Magnification, $\mathrm{x} 400$. Scale bars represent $200 \mu \mathrm{m}$. PZ, polaprezinc; H, high-dose; L, low-dose; UC, ulcerative colitis.

new dosage forms and new therapies based on the clinical manifestation of patients should allow for the identification of individual treatment protocols, which will be helpful to improve or cure the symptoms and intestinal lesions of patients with UC, and make the treatment of UC more economical and effective.

\section{Acknowledgements}

The authors thank Dr. Ziqiang Zhang of the Pathology Department, Chinese Academy of Medical Sciences and Peking Union Medical College for assistance with paraffin sectioning and H\&E staining. 


\section{Funding}

This study was supported by Jilin Province Broadwell Pharmaceutical Co., Ltd. (Changchun, China; grant no. 2017-08-14) and the Technology Innovation Fund for Enterprises (grant no. 2017-001).

\section{Availability of data and materials}

The datasets used and/or analyzed during the current study are available from the corresponding author on reasonable request.

\section{Authors' contributions}

$\mathrm{ZL}$ and $\mathrm{WX}$ performed molecular and animal experiments, arranged the data and revised the article; ML, ZL and WX analyzed and interpreted the data; JL performed molecular and animal experiments; ZL, ML designed the concept and wrote the manuscript; XL and TL participated in the molecular experiments. All of the authors have approved the final manuscript for publication.

\section{Ethics approval and consent to participate}

The animal use protocol in this study went through an Animal Experimental Ethical Inspection process and was reviewed and approved by the Animal Care \& Welfare Committee of the Chinese Academy of Medical Sciences-Peking Union Medical College.

\section{Patient consent for publication}

Not applicable.

\section{Competing interests}

One of the authors has received research grants from Jilin Province Broadwell Pharmaceutical Co., Ltd. The authors declare that they have no other competing interests.

\section{References}

1. Moura FA, de Andrade KQ, Dos Santos JCF, Araújo ORP and Goulart MOF: Antioxidant therapy for treatment of inflammatory bowel disease: Does it work? Redox Biol 6: 617-639, 2015.

2. Suh JH and Saba JD: Sphingosine-1-phosphate in inflammatory bowel disease and colitis-associated colon cancer: The fat's in the fire. Transl Cancer Res 4: 469-483, 2015.

3. Yang QF, Chen BL, Zhang QS, Zhu ZH, Hu B, He Y, Gao X, Wang YM, Hu PJ, Chen MH and Zeng ZR: Contribution of MDR1 gene polymorphisms on IBD predisposition and response to glucocorticoids in IBD in a Chinese population. J Dig Dis 16: 22-30, 2015.

4. Eichele DD and Kharbanda KK: Dextran sodium sulfate colitis murine model: An indispensable tool for advancing our understanding of inflammatory bowel diseases pathogenesis. World J Gastroenterol 23: 6016-6029, 2017.

5. Zhang ZL, Fan HY, Yang MY, Zhang ZK and Liu K: Therapeutic effect of a hydroxynaphthoquinone fraction on dextran sulfate sodium-induced ulcerative colitis. World J Gastroenterol 20 : 15310-15318, 2014

6. Däbritz J, Gerner P, Enninger A, Classen M and Radke M: Inflammatory bowel disease in childhood and adolescence. Dtsch Arztebl Int 114: 331-338, 2017.
7. Balfe A, Lennon G, Lavelle A, Docherty NG, Coffey JC, Sheahan K, Winter DC and O'Connell PR: Isolation and gene expression profiling of intestinal epithelial cells: Crypt isolation by calcium chelation from in vivo samples. Clin Exp Gastroenterol 11: 29-37, 2018.

8. Biasi F, Leonarduzzi G, Oteiza PI and Poli G: Inflammatory bowel disease: Mechanisms, redox considerations, and therapeutic targets. Antioxid Redox Signal 19: 1711-1747, 2013.

9. Yarlas A, D'Haens G, Willian MK and Teynor M: Health-related quality of life and work-related outcomes for patients with mild-to-moderate ulcerative colitis and remission status following short-term and long-term treatment with multimatrix mesalamine: A prospective, open-label study. Inflamm Bowel Dis 24: 450-463, 2018.

10. Oliveira L and Cohen RD: Maintaining remission in ulcerative colitis-role of once daily extended-release mesalamine. Drug Des Devel Ther 5: 111-116, 2011.

11. Ming LR, Wu Bin W and Tang Yao T: Safety and effectiveness of mesalazine in the treatment of ulcerative colitis: A systematic review. China Pharm 21: 4201-4204, 2010.

12. Algaba A, Guerra I, García García de Paredes A, Hernández Tejero M, Ferre C, Bonillo D, Aguilera L, López-Sanromán A and Bermejo F: What is the real-life maintenance mesalazine dose in ulcerative colitis? Rev Esp Enferm Dig 109: 114-121, 2017.

13. Ransford RA and Langman MJ: Sulphasalazine and mesalazine: Serious adverse reactions re-evaluated on the basis of suspected adverse reaction reports to the Committee on Safety of Medicines. Gut 51: 536-539, 2002.

14. Shimodate Y, Takanashi K, Waga E, Fujita T, Katsuki S and Nomura M: Exacerbation of bloody diarrhea as a side effect of mesalamine treatment of active ulcerative colitis. Case Rep Gastroenterol 5: 159-165, 2011.

15. Sehgal P, Colombel JF, Aboubakr A and Narula N: Systematic review: Safety of mesalazine in ulcerative colitis. Aliment Pharmacol Ther 47: 1597-1609, 2018.

16. Vaughn BP and Moss AC: Novel treatment options for ulcerative colitis. Clin Investig (Lond) 3: 1057-1069, 2013.

17. Takei M: Development of polaprezinc research. Yakugaku Zasshi 132: 271-277, 2012 (In Japanese).

18. Itagaki M, Saruta M, Saijo H, Mitobe J, Arihiro S, Matsuoka M, Kato T, Ikegami M, Tajiri H and Scand J: Efficacy of zinc-carnosine chelate compound, Polaprezinc, enemas in patients with ulcerative colitis. Scand J Gastroenterol 49: 164-72, 2014.

19. Ko JK and Leung CC: Ginger extract and polaprezinc exert gastroprotective actions by anti-oxidant and growth factor modulating effects in rats. J Gastroenterol Hepatol 25: 1861-1868, 2010.

20. Sakae K and Yanagisawa $\mathrm{H}$ : Oral treatment of pressure ulcers with polaprezinc (zinc L-carnosine complex): 8-week open-label trial. Biol Trace Elem Res 158: 280-288, 2014.

21. Feldman AT and Wolfe D: Tissue processing and hematoxylin and eosin staining. Methods Mol Biol 1180: 31-43, 2014.

22. Chassaing B, Aitken JD, Malleshappa M and Vijay-Kumar M: Dextran sulfate sodium (DSS)-induced colitis in mice. Curr Protoc Immunol 104: Unit 15.25, 2014.

23. Zhang Y, Okamura S, Kudo T, Masuo T and Mori M: Calcineurin inhibition by polaprezinc in rats with experimentally-induced colitis. Life Sci 88: 432-439, 2011.

24. Matsukura T and Tanaka H: Applicability of zinc complex of L-carnosine for medical use. Biochemistry (Mosc) 65: 817-823, 2000.

25. Ohkawara T, Nishihira J, Nagashima R, Takeda H and Asaka M: Polaprezinc protects human colon cells from oxidative injury induced by hydrogen peroxide: Relevant to cytoprotective heat shock proteins. World J Gastroenterol 12: 6178-6181, 2006.

26. Itagaki M, Saruta M, Saijo H, Mitobe J, Arihiro S, Matsuoka M, Kato T, Ikegami $\mathrm{M}$ and Tajiri $\mathrm{H}$ : Efficacy of zinc-carnosine chelate compound, Polaprezinc, enemas in patients with ulcerative colitis. Scand J Gastroenterol 49: 164-172, 2014.

27. Dong Z, Du L, Xu X, Yang Y, Wang H, Qu A, Qu X and Wang C: Aberrant expression of circulating Th17, Th1 and Tc1 cells in patients with active and inactive ulcerative colitis. Int J Mol Med 31: 989-997, 2013.

28. Murakami-Nakayama M, Tsubota M, Hiruma S, Sekiguchi F, Matsuyama K, Kimura T, Moriyama M and Kawabata A: Polaprezinc attenuates cyclophosphamide-induced cystitis and related bladder pain in mice. J Pharmacol Sci 127: 223-228, 2015. 
29. McDaniel DK, Eden K, Ringel VM and Allen IC: Emerging roles for noncanonical NF- $\mathrm{KB}$ signaling in the modulation of inflammatory bowel disease pathobiology. Inflamm Bowel Dis 22: 2265-2279, 2016.

30. Kruis W, Kiudelis G and Racz I: Once daily versus three times daily mesalazine granules in active ulcerative colitis: A doube-blind, double-dummy, randomized, non-inferiority trial. Gut 58: 233-237, 2009.

31. Sanchez-Munoz F, Dominguez-Lopez A and YamamotoFurusho JK: Role of cytokines in inflammatory bowel disease. World J Gastroenterol 14: 4280-4288, 2008.

32. Zhao X, Li J, Meng Y, Cao M and Wang J: Treatment effects of jinlingzi powder and its extractive components on gastric ulcer induced by acetic acid in rats. Evid Based Complement Alternat Med 2019: 7365841, 2019.

33. Fausel R and Afzali A: Biologics in the management of ulcerative colitis-comparative safety and efficacy of TNF- $\alpha$ antagonists. Ther Clin Risk Manag 11: 63-73, 2015.

34. Arrigo P: Pathology-dependent effects linked to small heat shock proteins expression: An Update. Scientifica (Cairo) 2012: 185641, 2012.
35. Gupta R, Chaudhary AR, Shah BN, Jadhav AV, Zambad SP, Gupta RC, Deshpande S, Chauthaiwale V and Dutt C: Therapeutic treatment with a novel hypoxia-inducible factor hydroxylase inhibitor (TRC160334) ameliorates murine colitis. Clin Exp Gastroenterol 7: 13-23, 2014.

36. Moghadamtousi SZ, Rouhollahi E, Karimian H, Fadaeinasab M, Abdulla MA and Kadir HA: Gastroprotective activity of Annona muricata leaves against ethanol-induced gastric injury in rats via Hsp70/Bax involvement. Drug Des Devel Ther 8: 2099-2110, 2014

37. Ono K, Nimura S, Hideshima Y, Nabeshima K and Nakashima M: Orally administered sodium 4-phenylbutyrate suppresses the development of dextran sulfate sodium-induced colitis in mice. Exp Ther Med 14: 5485-5490, 2017.

38. Yu Q, Mao R, Lian L, Ng SC, Zhang S, Chen Z, Zhang Y, Qiu Y, Chen B, He Y, et al: Surgical management of inflammatory bowel disease in China: A systematic review of two decades. Intest Res 14: 322-332, 2016.

39. Zhai H, Liu A, Huang W, Liu X, Feng S, Wu J, Yao Y, Wang C, Li Q, Hao Q, et al: Increasing rate of inflammatory bowel disease: A 12-year retrospective study in NingXia, China. BMC Gastroenterol 16: 2, 2016. 